\title{
The importance of adolescent girls and "epidemic gearing" on HIV prevalence across West Africa
}

Holly J Prudden ${ }^{1}$, Zindoga Mukandavire ${ }^{2}$, Marelize Gorgens ${ }^{3}$, David Wilson ${ }^{3}$, Jasmina Panovska-Griffiths ${ }^{1,4,5}$, Charlotte Watts ${ }^{1,6}$

${ }^{1}$ Department of Global Health and Development, London School of Hygiene and Tropical Medicine, London. UK.

${ }^{2}$ School of Computing, Electronics and Maths, University of Coventry, UK

${ }^{3}$ The World Bank, Washington DC. USA

${ }^{4}$ Department of Applied Health Research, University College London, London. UK.

${ }^{5}$ Institute for Global Health, University College London, London. UK.

${ }^{6}$ Departement for International Development, UK

Corresponding author: j.panovska-griffiths@ucl.ac.uk 


\section{Abstract}

\section{Background}

In West Africa HIV prevalence varies between $0.1-6 \%$ in female and between $0.1-4 \%$ in the male general population. Male circumcision is almost universal, and it is unclear what drives this variation. We use mathematical modelling to identify the determinants of this variation across fourteen West African countries.

\section{Methods}

We developed a novel dynamic model of HIV transmission between population cohorts of female sex workers (FSWs), their clients, females with $2+$ partners in the past year and other sexually active women and men in the general population. Parameter ranges were determined from the literature and sampled using Latin Hypercube sampling to identify parameter sets that fit West African HIV prevalence data. Partial-rank correlation coefficients between different model parameters and the HIV prevalence in general male and female population across 14 countries were calculated to determine to most significantly correlated model parameters to HIV prevalence.

\section{Results}

The key determinant of HIV in females when prevalence is between $0-3 \%$ is the size of the brothel and non-brothel FSW groups. When female HIV prevalence $>3 \%$, the percentage of sexually active adolescent females with $2+$ partners has greater influence on HIV prevalence. The size of the FSW groups has the most significant impact on HIV prevalence for males.

\section{Conclusions}

Our findings confirm the role of FSWs in West Africa as an important determinant of HIV risk, but also identify, in countries with higher HIV prevalence, the emerging role of a group of adolescent girls with $2+$ partners is an important determinant of risk. In fact, our findings suggest that this group may enable the epidemic to be effectively "geared up" when partnerships are formed with higher-risk males, indicating additional prevention needs amongst this group.

\section{Funding}

This study was funded by UNAIDS. 


\section{Introduction}

2 HIV in West Africa accounts for around $20 \%$ of all infections in sub-Saharan Africa with

3 HIV prevalence here generally lower than in other African regions [1] most likely as a result

4 of the almost universal practice of male circumcision across West Africa [2]. Around 30\% of

5 all AIDS-related deaths worldwide occur in West Africa with reported 280,000 AIDS-related

6 deaths in 2017 [3]but are significant variations in HIV prevalence between countries (Figure

7 1). The National Demographic and Health Surveys (DHS) suggest that Nigeria, Cote d'Ivoire

8 and Cameroon have the highest HIV prevalence levels (4-6\% among females and 2-4\% in

9 males) in comparison to other countries (0.5-3\% amongst both females and males [4,5]

11 Recent UNAIDS reports suggest that women are disproportionately affected by HIV in West 12 and Central Africa and account for around 57\% of adults living with HIV in 2017. The

13 average HIV prevalence stands at $2.3 \%$ among adult women (15-49 years old), compared to

$141.6 \%$ among adult men (15-49 years old) [4]. In addition, reports suggest that adolescent girls

15 and young women (aged 15-24) are disproportionately more likely to acquire HIV than their

16 male counterparts [4].

18 Past epidemiological studies from this region have suggested that commercial sex is a major 19 driver of the HIV epidemic [5] and that interventions focused on female sex workers (FSWs) 20 and their clients are highly effective at reducing the prevalence of sexually transmitted 21 infections (STIs) [5]. In addition, a mathematical modelling study has suggested commercial 22 sex work as a major driver of both the short and longer term epidemic trajectories in the 23 region [6]. However, our ecological analysis of variations in population prevalence levels 24 across West Africa highlight that, along with female commercial sex work, variations in HIV 25 prevalence amongst general population males and females between countries may be 26 associated with national variations in the percentage of younger females (15-24 years) that 27 have 2 or more (2+) partners in the past year, as defined by Demographic Health surveys [7].

28 The role of this adolescent girls group has previously been mentioned as a key population for 29 HIV control [8].

31 Our work expands this idea and aims to explore the role of this group of younger females 32 (15-24 years) that have 2 or more (2+) partners, in describing the variations in HIV 33 prevalence among different countries in West Africa. The overall aim of this work is to 
34 identify the potential determinants of population variation in HIV prevalence among the 35 female and male general population in West Africa, considering 14 countries in the region.

36 Unlike our previous work [7], that focused on ecological analysis, here, we developed and 37 applied a dynamic model for HIV transmission between different cohorts at risk of acquiring 38 HIV in West Africa. Based on existing literature and work to date, we included cohorts of 39 FSW, clients and the general population. The novelty of our work is that, unlike previous 40 studies, within our model we incorporated a cohort of sexually active adolescent females with 41 multiple $(2+)$ partners in the past year and allowed the model to have a proportionate mixing 42 pattern rather than a standard one. This means sexual partnerships between females 2+, 43 clients and males $2+$ were distributed proportionately based on their number of partners (as 44 opposed to having a fixed number of sexual partners for each group). Including this group of 45 females with $2+$ partners and the proportionate mixing pattern within a dynamic transmission 46 model, allowed us to model the groups' interactions with other population cohorts and hence 47 explore their role in describing the variations of HIV prevalence in West Africa.

\section{Methods}

49 The methodology for this work is described in Figure 2(a) with the novel proportionate 50 mixing pattern illustrated in Figure 2(b).

\section{Model design}

53 We developed a deterministic compartmental model describing the transmission of HIV 54 infection among sexually active 15-49 year olds. The mathematical framework and model 55 equations are detailed in Appendix 1. In summary, the model stratifies the sexually active 56 population into two groups of female sex workers (brothel-based and non-brothel based) and their respective client partner groups. In addition, the model includes a separate group of adolescent females with $2+$ non-commercial sexual partnerships in the past year and a group of males (15-49) with 2+ non-commercial sex worker partners in the past year, as well as subgroups representing other sexually active men and women in the general population. In order to explore the population sexual mixing pattern that best represents West Africa, we

62 introduced a mixing matrix based on a "fixed proportionate" mixing scenario (depicted in

63 Figure 2(b)). Here, we created an additional parameter, $\zeta$, to represent the proportion of 64 partnerships females 2+ have with men who are also clients (of either brothel-based or non65 brothel based FSW). This parameter was also sampled in the course of the uncertainty analysis. 


\section{Model Parameterisation}

69 Biological, epidemiological parameter data and published developmental indicators for West

70 Africa were extracted from the literature. A full parameter table, including additional 71 information on the computation and extraction of data is provided in Appendix 1. Table 1

72 below is a shortened version of the table showing only the parameters that were used as

73 model inputs for our statistical uncertainty analysis. Based on the data from DHS surveys

74 across the region we assume the entire male population are circumcised [9]. The probability

75 of transmission per act is estimated using a wide range and this incorporates the potential

76 presence of sexually transmitted infections, anal sex acts (in addition to vaginal sex acts) and

77 the effects of anti-retroviral therapy, which is introduced into the model 20 years after the start of the epidemic.

\section{Uncertainty analysis and model calibration}

81 For each of these parameters in Table 1, we generated a range of plausible estimates from the 82 literature to account for the parameter variations across West African countries. We then 83 sampled within each parameter range (splitting it uniformly into 40,000 samples) using a 84 Latin Hypercube sampling [10] to generate 800,000 parameter combinations as inputs to the mathematical model. For each parameter combination, the model was solved numerically in $\mathrm{R}$ programming environment until HIV steady state across the different population cohorts was achieved. To calibrate the model, only the projections where HIV prevalence was within the literature-reported ranges for West Africa in 2017 (as per Figure 1 generated with data from $[11,12]$ were retained. Specifically, model projected HIV prevalence of $0.5-6 \%$ in the general female population, $0.5-4 \%$ in the general male population, $15-48 \%$ in the brothelbased FSW group and 10-25\% in the non-brothel based FSW group were kept as model fits and to reflect the HIV prevalence in West African in Figure 1. No fitting criteria were applied to the female 2+ group, male 2+ group or the brothel-based FSW clients and non-brothel based FSW client groups due to the provision of insufficient data for these subgroups.

\section{Correlation analysis}

97 Among the projected model outcomes we assessed the correlation of different model

98 parameters with the HIV prevalence among the general male and female population. We 99 computed the partial rank correlation coefficient (PRCC) between the different model 100 parameters and, for those where there was correlation, the statistical significance (p-value) of 
101 the correlation with male and female HIV prevalence. By doing this we characterised the 102 linear relationship between the different parameter inputs and different HIV prevalence 103 values that correspond to values within West Africa. This analysis was run in Stata v14.

104 We considered the correlation in different HIV prevalence brackets: firstly assessing the full 105 range of HIV prevalence in males (0.1-4\%) and females (0.1-6\%). Then, given the variation 106 in the HIV prevalence amongst females and males in West Africa across the different 14 107 countries, we considered three HIV prevalence categories for females $\{0.1-2 \%, 2-3 \%, 3-6 \%\}$ 108 and males $\{0.1-2 \%, 2-3 \%, 3-4 \%\}$

111 Overall, for model projected HIV prevalence to be $0.1-4 \%$ in the males, $0.1-6 \%$ in females, $11215-48 \%$ in the brothel-based FSW group and 10-25\% in the non-brothel based FSW group, 113 the model generated a total of 11,164 fits. Tables 2 and 3 contain the results of the correlation 114 analysis between HIV prevalence among females and males in 14 West African countries and 115 the model parameters. Figure 3(a)-(b) show the graphical representation of the results from 116 Tables 2 and 3, with the inner ring in each Figure containing the results from Table 2 and the 117 outer ring containing the results from Table 3.

\section{Key determinants of HIV prevalence in females}

120 When we consider all countries collectively, where HIV prevalence among the female 121 general population ranges from 0.1-6\% (Table 2 and Figure 3(a) inner ring), the size of the 122 population of the female $2+$ group $\left(p_{F T S}\right)$ emerges as the most significant determinant of HIV 123 prevalence among females. Of importance is also the number of sexual partners this group 124 has $\left(C_{C T S}^{T S}\right)$, as well as the size of the non-brothel based sex-worker group $\left(p_{F N B}\right)$ and the 125 parameter $(\xi)$ that describes the proportion of sex acts females 2+ have with clients of FSWs 126 (as opposed to their corresponding males 2+ group). The size of the brothel based FSW 127 groups $\left(P_{F B B}\right)$ is also positively and significantly correlated with HIV prevalence among the 128 females, highlighting the importance of the relative size of all sexually active female 129 population groups.

130 In 9 out of the 14 countries, HIV prevalence among females is low (0.1-2\%) and female HIV 131 prevalence is most strongly correlated to the size of both brothel-based and non-brothel based 132 FSW groups $\left(p_{F N B}\right.$ and $\left.p_{F B B}\right)$ and to a lesser extent to the size of the group of females with $1332+$ partners $\left(p_{F T S}\right)$ (Figure 3(b)). However, the mixing pattern via the parameter $(\xi)$ and the 
134 number of sexual partners of the female $2+$ group $\left(C_{C T S}^{T S}\right)$ do remain positively correlated to 135 female HIV prevalence here (Table 2; $2^{\text {nd }}$ row and Figure 3(b) inner ring). The results are 136 similar in countries ( 2 out of 14 ) where HIV prevalence is between 2-3\%, with the size of the 137 FSW $\left(P_{F N B}, P_{F B B}\right)$ groups most significantly correlated to HIV prevalence in females, and the 138 size of the female 2+ group less important. Partnership numbers and duration of being a 139 member of a higher-risk group (respectively $\xi$ and $C_{C T S}^{T S}$ ) (Table $2 ; 3^{\text {rd }}$ row; Figure 3(c) inner 140 ring), become more important factors in countries where HIV prevalence is slightly higher. 141 For countries in which female general population HIV prevalence is within the highest 142 prevalence range, $3-6 \%$ (3 out of 14 countries), the model indicates that the size of the female $1432+$ group $\left(P_{F T S}\right)$ is most strongly associated with HIV prevalence (Figure 3(d) inner ring). 144 The parameter describing the proportion of partnerships females with $2+$ partners form $(\xi)$ 145 with clients of FSWs, continues to be an important driver of HIV prevalence, while the size 146 of the FSW groups becomes relatively less significant. This final observation is partly seen 147 because the size of the FSW groups within the model are constrained, based on evidence from surveys.

Key determinants of HIV prevalence in males

152 For males, HIV prevalence ranges from $0.1-4 \%$ across the 14 countries. Our results show that 153 the population size of the FSW groups (both brothel and non-brothel based; respectively $154 P_{F B B}$ and $\left.P_{F N B}\right)$ is the most important determinant of HIV prevalence for the male general 155 population in West Africa (Figures 3(a)-(d) outer ring). The number of client partners that sex workers have $\left(C_{F B B}^{C}\right)$ and the transmission probability of acquiring HIV as a female from a male partner $\left(\beta_{m f}\right)$ (Figure 3(a) outer ring) are important. The number of sexual partners of 158 females $2+\left(C_{C T S}^{T S}\right)$ and the size of the population size of female $2+\left(P_{F T S}\right)$ are also positively corelated with male HIV prevalence but to a lesser extend (Table 3 ), as is the parameter $(\xi)$ that describes the proportion of sex acts females 2+ have with clients of FSWs.

161 In West African countries with lower HIV prevalence among the male general population (0$1622 \%$ in 12 out of 14 countries), we observe that the most relevant determinant of HIV 163 prevalence is the population size of non-brothel-based FSWs $\left(P_{F N B}\right)$ and brothel based FSW $164\left(P_{F B B}\right)$. In countries with higher HIV prevalence in the male general population (2-3\% in 1 of 16514 countries) the size of the FSWs groups $\left(P_{F N B}\right.$ and $\left.P_{F B B}\right)$ remains important, with the number of partners of Females $2+$ partners $\left(C_{C T S}^{T S}\right)$ and the condom use among non-brothel 
based FSWs $\left(f_{F N B}\right)$ also correlated but to a lesser extent (Table 3 and outer ring of Figure 3(c)). Finally, in countries with higher HIV prevalence among the male general population (3-4\%, 1 of 14 countries) only two parameters describing the size of the two FSW groups significantly affect the HIV prevalence in males (Table 3; last row and outer ring of Figure $3(d)))$.

\section{Discussion}

Our results suggest that as female HIV prevalence increases across different West African countries, from $0.1-2 \%$ (in 9 out of 14 countries) through to $2-3 \%$ ( 2 out of 14 country) and then $3-6 \%$ (in 3 out of 14 country), the correlation between the parameters associated with the groups of female with $2+$ partners and the HIV prevalence among females increases (results within the inner ring of Figure 3(a)-(d) and pictorially represented in Figure 4). Therefore, our results suggest that this group of females with $2+$ partners, may have a gearing-type role in sustaining high HIV prevalence among females in West Africa.

In contrast, as male HIV prevalence increases, from $0.1-2 \%$ (in 12/14 countries) through to $2-3 \%$ (1/14 country) and then $3-4 \%$ (in $1 / 14$ country), the correlation between the parameters associated with the FSWs groups and the HIV prevalence among males increases (results within the outer ring of Figure 3(a)-(d) and pictorially represented in Figure 4). Therefore, our results show that the size of the FSW groups and their sexual activity may be more responsible for sustaining high HIV prevalence among males in West Africa.

Past studies have emphasised the importance of sex work and other vulnerable groups as key determinants of HIV prevalence [13] to sustain HIV prevalence of 0-3\% among the general population [6] and demonstrated that the size of the FSW population (relative to the total population) is the most important determinant of HIV prevalence [14]. The findings from our study show that whilst (brothel and non-brothel) sex work is an important determinant of HIV prevalence in both females and males across the 14 West African countries, the size of the female 2+ group, also emerges as an important determinant of HIV prevalence, particularly for countries with higher prevalence levels and among the female HIV prevalence. For lower level epidemics in most countries, the size of FSW groups remains the key determinant in agreement with the findings of [14]. However, when stratifying the HIV epidemics into 
200 respective categories of HIV prevalence in both males and females, we provide evidence of a 201 potential transitionary phrase within an epidemic which we depicted in Figure 4. This is an interesting hypothesis which potentially highlights a change in the nature of an HIV epidemic 203 (perhaps more formally known as going from being a 'concentrated' to a 'generalised' 204 epidemic, as characterised by UNAIDS), from one being more dependent on the size and 205 sexual activity of female sex workers, to an epidemic in which the subgroup size and sexual activity of young females, with multiple partners, is of equal importance. This same transition is not seen when the analysis is repeated for males, which aligns more consistently with the theory of a larger population of male clients acting as a 'bridge' to female partners. Whilst traditionally in modelling analyses, these females were thought to be 'long term' steady partners, our analysis suggests that younger more vulnerable females could also act as a

211 highly vulnerable group for acquiring new HIV infections, particularly if they are forming 212 partnerships with men who are also clients of FSWs.

214 The findings from this analysis are important. Firstly, they confirm three previous findings:

215 (a) that commercial sex work remains important for HIV transmission in West Africa, 216 particularly in lower level epidemics and for sustaining HIV prevalence among the male 217 general populations, in agreement with previous findings [14] (b) that when HIV prevalence 218 is high amongst FSWs, a large proportion of HIV infections may be attributable to these 219 groups alone and is in line with previous findings [15]; and (c) they support the hypothesis on 220 the importance of behaviours that modify the risk of acquiring infection (e.g. fewer partner 221 numbers, shorter durations in sex work and higher levels of condom use) as protective 222 barriers against infection. Secondly, our results are in support of the idea of a type of 223 "epidemic gearing" effect depicted in Figure 4. This will imply that, for the epidemic to have 224 the propensity to grow, it needs to be effectively "geared up", firstly, by smaller high-sexual 225 activity groups of FSWs, and then secondly, through the larger subgroup of adolescent 226 females $2+$, which act as an additional larger "cog" in the epidemic chain enabling the epidemic to achieve higher-levels of HIV prevalence (Figure 4). Here the concept of behavioural heterogeneity and the importance of approaches that seek to identify high-risk individuals and understanding the structure of sexual networks emerge as important.

Although our results are important, for epidemics in countries where HIV prevalence is high 232 (e.g. higher than 4\% in West Africa), transmission pathways may require a more advanced 233 understanding of the underlying factors driving the epidemic. We strongly support the 
234 collection of more behavioural data to better understand and inform these pathways, and 235 advocate for closer collaborations between modellers and social scientists, so that 236 mathematical model structures better reflect the true dynamics of HIV epidemics.

238 Our analysis does have several limitations. Estimates on the percentage of adolescent females 239 reporting $2+$ partners is mostly extracted from the DHS data. Whilst there is some 240 comparability internally and between countries, typically questions on sexual behaviours are 241 prone to under-reporting, especially amongst women. All results should be interpreted with 242 caution, and the nature of the findings are partly a consequence of the model's structure, 243 although we believe this to be a more useful representation of sexual networks and 244 transmission pathways, supported by evidence both from the modelling and social science 245 literature.

247 Population data from DHS surveys suggests that the percentage of adolescent females with 248 multiple partners, may comprise up to $9 \%$ of the total female population, with other studies 249 reporting higher percentages [16-18]. This modelling study, shows the importance of the size 250 and sexual activity of the female $2+$ group and more broadly the need to assess and 251 understand behaviours that shape sexual network structures as well as those that modify the 252 risks of acquiring infection, in determining variations in HIV prevalence. However, to date, 253 very few mathematical models of HIV transmission in the general population explicitly 254 include or recognise the importance of an adolescent female 2+ group, despite the high levels 255 of incidence in this population. In addition, more accurate data on the estimated subgroup 256 size for high-risk groups of female sex workers is often absent from modelling studies, 257 despite demonstrating here the fundamental importance of this.

258 In our correlation analysis we have chosen to use PRCC rather than other correlation 259 coefficients, as we believe that it provides good insight on the global sensitivity of the system 260 and projects the parameters that are most influential (or significant) even if other parameters 261 are simultaneously perturbed. Other correlation analysis (e.g. Pearson correlation) are more 262 based on local sensitivity calculations and can provide insight into small perturbations around 263 the key parameters, but can often ignore the impact of large perturbations, something we 264 wanted to include. Future analysis will consider contrasting different correlation measures 265 and discuss the differences in the findings. 
267 Our findings have the potential to have important implications for future policy. The

268 UNAIDS definition for a concentrated epidemic is one in which HIV prevalence is less than

$2691 \%$ in the general population and over 5\% prevalence in key risk groups such as FSWs, with

270 the caveat being that no subpopulation is fully self-contained and these thresholds should be

271 interpreted with caution [19]. However, here we demonstrate the dangers of such rigid

272 definitions, by highlighting the subtle maturity that may occur in epidemics from those driven

273 predominantly by commercial sex work, to those in which both the role of commercial sex

274 and the size and sexual behaviours of other populations is important. The social science

275 literature should be a greater source of information, highlighting in particular the

276 vulnerability of young females [20,21].

277

278 Finally, despite much focus on interventions being towards reducing the biological 279 probability of transmission, our findings suggest that programmes which result in fewer 280 women practicing sex work and fewer young females engaging in higher-risk partnerships, 281 could play a key role in reducing the size of the HIV epidemics in West Africa. In the future, 282 sex work may become less prevalence as women become more empowered with better 283 education, jobs and earning potential as African countries continues to develop. Future 284 policies on HIV should focus on treatment, prevention, but also key aspects of women's 285 development, to ensure they are able to make the best most informed decisions.

288 This study was funded by UNAIDS and supported by the STRIVE research programme 289 consortium within London School of Hygiene and Tropical Medicine funded by the 290 Department for International Development. JPG's work was funded by the National Institute 291 for Health Research (NIHR) Collaboration for Leadership in Applied Health Research and 292 Care North Thames at Barts Health NHS Trust. The views expressed are those of the authors 293 and not necessarily those of the NHS, the NIHR, the Department of Health and Social Care, 294 the Department for International Development or UNAIDS.

\section{Acknowledgements}

297 We would like to thank Prof Peter Vickerman (University of Bristol) and Dr Kate Mitchell

298 (Imperial College London) for their early contributions to this work, to Prof Timothy Hallett 299 (Imperial College London) and Dr Deirdre Hollingsworth (Warwick University) for their 
medRxiv preprint doi: https://doi.org/10.1101/19008839; this version posted October 18, 2019. The copyright holder for this preprint (which was not certified by peer review) is the author/funder, who has granted medRxiv a license to display the preprint in perpetuity. All rights reserved. No reuse allowed without permission.

300 contributions the methodology of the correlation analysis and to Prof Graham Medley 301 (LSHTM) for his insightful contribution to discussion of the interpretation of the findings 302 from this study.

303

304 Competing interests statement

305 No authors have competing interests. 


\section{References}

1. UNAIDS special report: How Africa turned AIDS around, available on

http://www.unaids.org/en/media/unaids/contentassets/documents/unaidspublication/2013/20130521_ Update Africa.pdf (accessed 20/09/2019)

2. Weiss HA, Quigley MA, Hayes, RJ 2000. Male circumcision and risk of HIV infection in sub Saharan Africa: a systematic review and meta-analysis. AIDS., 20, 2361-70.

3. UNAIDS 2017. UNAIDS special report. Ending AIDS: Progress towards 90-90-90 targets. https://www.unaids.org/sites/default/files/media_asset/Global_AIDS_update_2017_en.pdf (accessed October 2018)

4. Beattie T, Bobrova N, D, Watts C. Sex work typologies in West Africa: a literature review and discussion of the implications for HIV modelling. 2011. In: LONDON SCHOOL OF HYGIENE AND TROPICAL MEDICINE (ed.). London School of Hygiene and Tropical Medicine and The World Bank.

5. Lowndes CM, Alary M, Labbé AC, Gnintoungbè C, Belleau M, Mukenge L, Meda H, Ndour M, Anagonou S, Gbaguidi A. Interventions among male clients of female sex workers in Benin, West Africa: an essential component of targeted HIV preventive interventions. Sex Transm Infect, 83, 577-581.

6. Boily MC, Pickles M, Alary M, Baral S, Blanchard J, Moses S, Vickerman P, Mishra S. What Really Is a Concentrated HIV Epidemic and What Does It Mean for West and Central Africa? Insights From Mathematical Modeling. J Acquir Immune Defic Syndr, 68 Suppl 2, S74-82.

7. Prudden H, Beattie T, Bobrova N, Panovska-Griffiths J, Mukandavire Z, Gorgens M, Wilson D, Watts C. Factors associated with variations in population HIV prevalence across West Africa? Findings from an ecological analysis PLoS One. (2015) 10(12):e0142601.

8. Dellar RC, Dlamini S, Karin QA. Adolescent girls and young women: key populations for epidemic control. JAIDS 2015. 18(51); doi: 10.7448/IAS.18.2.19408

9. USAID. Demographic and Health Surveys [Online]. Available: http://dhsprogram.com/data/ (accessed 16/01/2019).

10. Fenniak M. 2004. Latin Hypercube Sampling [Online]. Available:

http://mathieu.fenniak.net/latin-hypercube-sampling/. (accessed 20/09/2019)

11.Report on HIV prevalence in Nigeria. 2017.

https://www.childrenandaids.org/sites/default/files/2017-11/NATIONAL-HIV-AND-AIDS-

STRATEGIC-FRAMEWORK.pdf, (accessed 15/06/2019). 
12. Report on HIV data across West African countries. UNAIDS 2017.

https://www.unaids.org/en/regionscountries/westandcentralafrica, (accessed 20/06/2019)

13. Lowndes $\mathrm{CM}^{1}$, Alary M, Meda H, Gnintoungbé CA, Mukenge-Tshibaka L, Adjovi

C, Buvé A, Morison L, Laourou M, Kanhonou L, A. Role of core and bridging groups in the transmission dynamics of HIV and STIs in Cotonou, Benin, West Africa. 2002. Sex Transm Infect, 78, i69-77.

14. Ghani, AC, Aral SO. Patterns of Sex Worker-Client Contacts and Their Implications for the Persistence of Sexually Transmitted Infections. 2005. Journal of Infectious Diseases, 191, S34-S41

15. Wilson D 2006. HIV Epidemiology: A review of recent trends and lessons. In: THE WORLD BANK (ed.) Global HIV/AIDS Program

16. Atwood KA, Kennedy SB, Shamblen S, Taylor CH, Quaqua M,Bee EM, Gobeh ME, Woods

DV, Dennis B. Reducing sexual risk taking behaviors among adolescents who engage in transactional sex in post-conflict Liberia. 2012. Vulnerable Child Youth Stud, 7, 55-65. 17. Moore AM, Biddlecom AE, Zulu EM. Prevalence and meanings of exchange of money or gifts for sex in unmarried adolescent sexual relationships in sub-Saharan Africa. 2007. Afr J Reprod Health, 11, 44-61.

18. Owoaje ET, Uchendu OC. Sexual risk behaviour of street youths in south west Nigeria. 2009. East Afr J Public Health, 6, 274-9.

19.UNAIDS. 2011. Terminology Guidelines [Online]. Available:

http://www.unaids.org/en/media/unaids/contentassets/documents/unaidspublication/2011/JC2118_ter minology-guidelines_en.pdf

20. Luke N. Age and Economic Asymmetries in the Sexual Relationships of Adolescent Girls in Sub-Saharan Africa. 2003. Studies in Family Planning, 34, 67-86.

21. Luke N, Kurz KM. Cross-generational and Transactional Sexual Relations in Sub-

Saharan Africa Washington DC: ICRW. 2002. 


\section{FIGURES}

Figure 1(a) and (b) HIV prevalence in the general adult female (a) and male (b) populations across 14 West African countries. HIV prevalence data is taken from UNAIDS report https://www.avert.org/hiv-and-aids-west-and-central-africa-overview from 2017

Figure 2 (a): Description of the methodology for this paper. (b) Sexual mixing patterns in the population. Black arrow denote partnership: Sexual partnerships exist between the two FSW groups and their respective client groups and between clients and females with $2+$ partners. Younger females 2+ also partner with males 2+. Separate groups of general population males and females form partnerships with one another, with a given proportion also having longer term partnerships with clients (in the case of females) and FSW (in the case of males (to represent the wives of clients and husbands of sex workers, respectively).

Figure 3: (a)-(d): Bar charts of the partial rank correlation coefficient (PRCC) between a selection of model parameters from Table 1 and the HIV prevalence in female and male general population across different HIV prevalence brackets. The absolute values of the PRCC are shown in Tables 2 and 3, and we only consider parameters that significantly influence the HIV prevalence (p-value <0.05).

Figure 4: Conceptual idea of the "epidemic gearing" effect of HIV epidemics in West Africa (the black dashed lines represent the "gearing effect" of the epidemic, by representing the sexual network connections between risk groups in the population)

\section{TABLES}

Table 1:Biological and behavioural parameter estimates and ranges for countries across the West Africa region with ranges derived from existing literature.

Table 2: Results from the correlation analysis across different HIV prevalence ranges for the female population and across different West African countries that fit with these ranges. We project the impact and significance of the key model parameters. 
medRxiv preprint doi: https://doi.org/10.1101/19008839; this version posted October 18, 2019. The copyright holder for this preprint (which was not certified by peer review) is the author/funder, who has granted medRxiv a license to display the preprint in perpetuity.

All rights reserved. No reuse allowed without permission.

Table 3: Results from the correlation analysis across different HIV prevalence ranges for the male population and across different West African countries that fit with these ranges. We project the impact and significance of the key model parameters.

Supplementary Material

Appendix A: Description of the novel mathematical model for HIV transmission in West Africa

Supplementary Table S1: Model parameters and their values 


\section{(a) HIV prevalence in woman adult population}

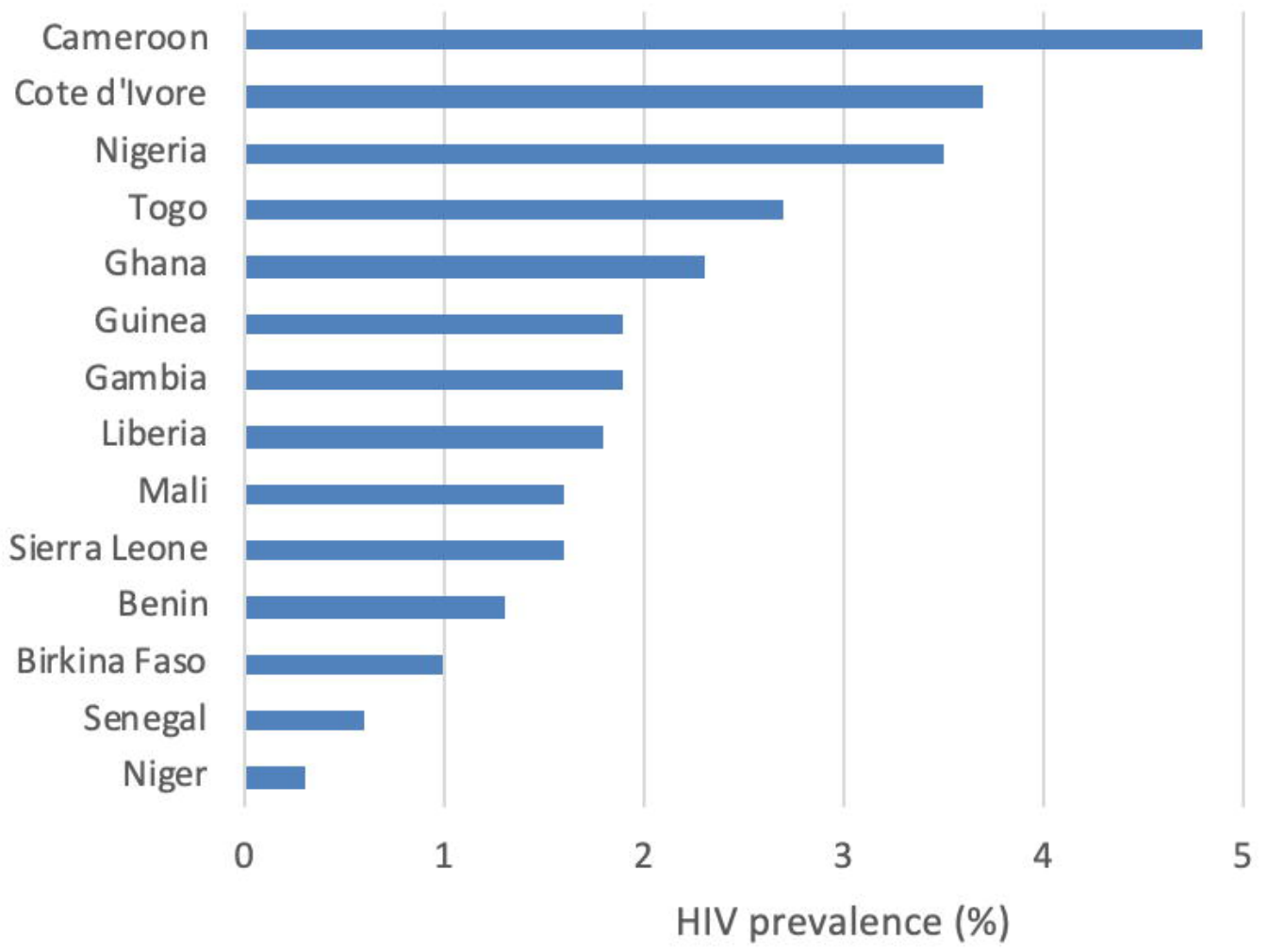




\section{(b) HIV prevalence in male adult population}

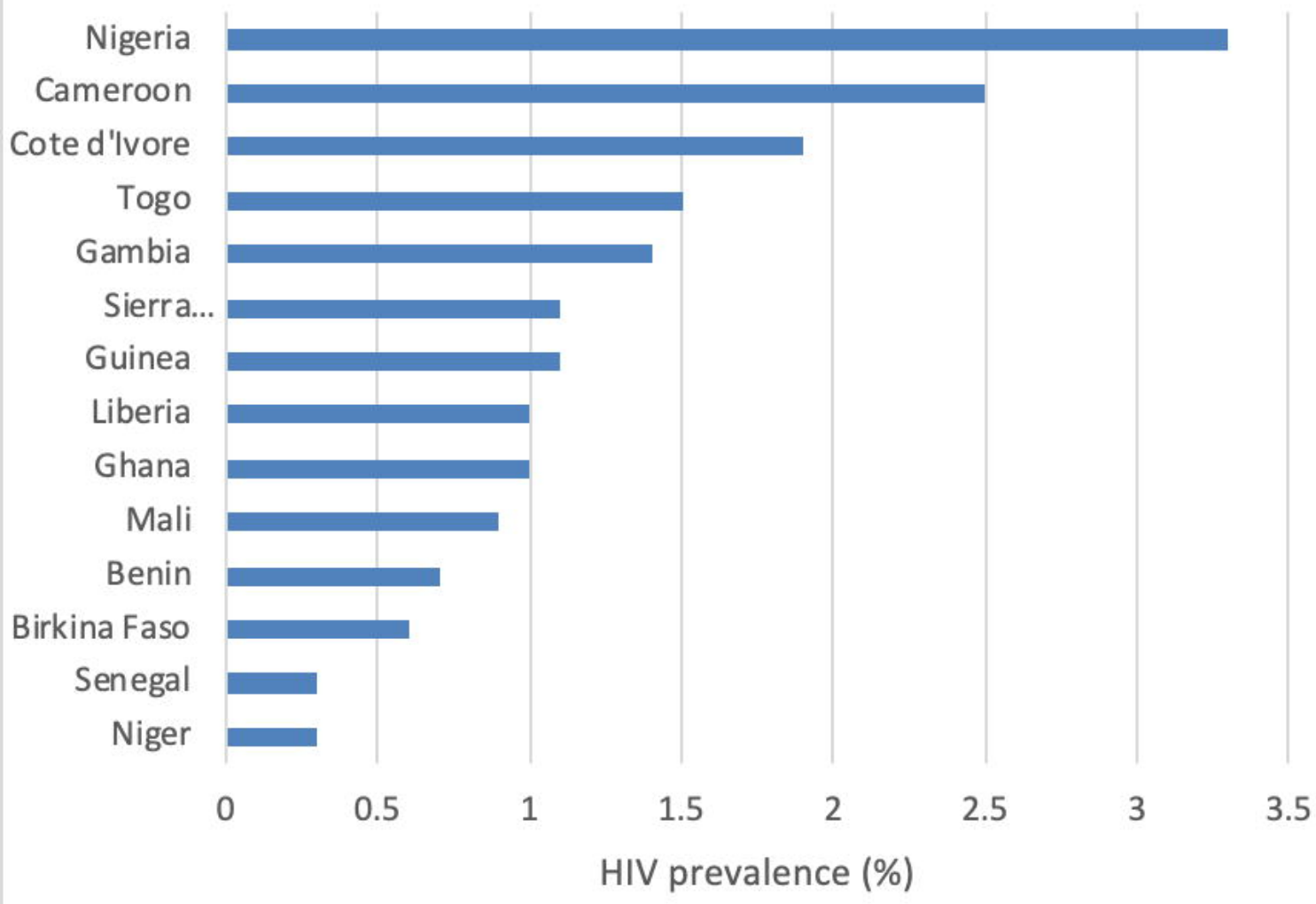




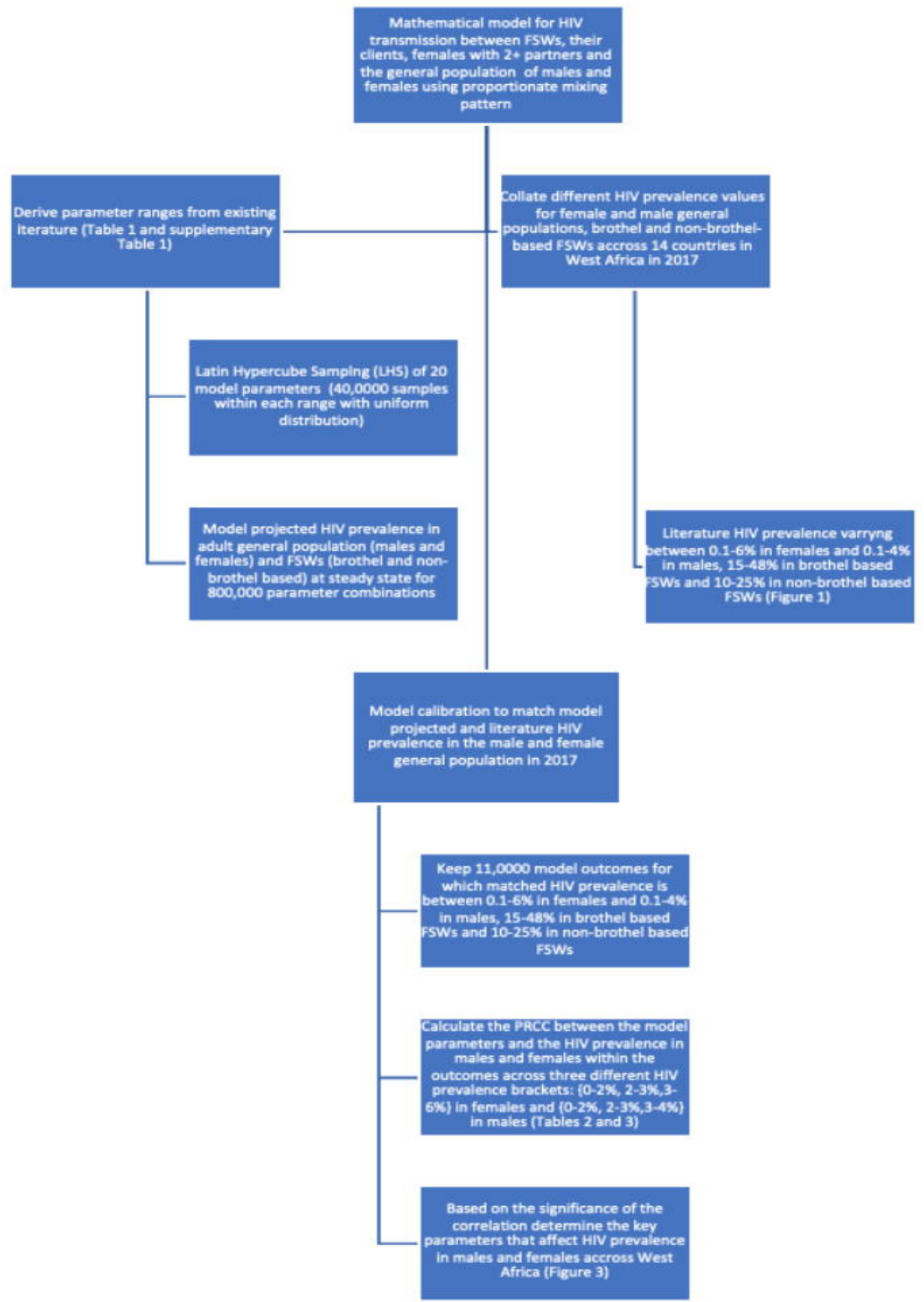




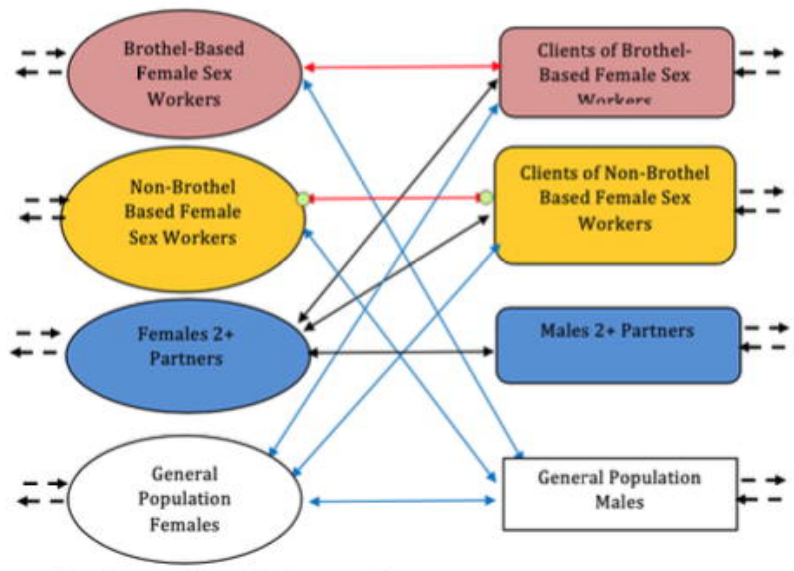

$\longleftrightarrow$ Sexual partnerships of female sex workers

$\longleftrightarrow$ Sexual partnerships of females $2+$

$\longleftrightarrow$ Sexual partnerships of members of the general population

$\rightarrow$ Individuals move in, out and between groups 

prevalence in females

- Pfnb

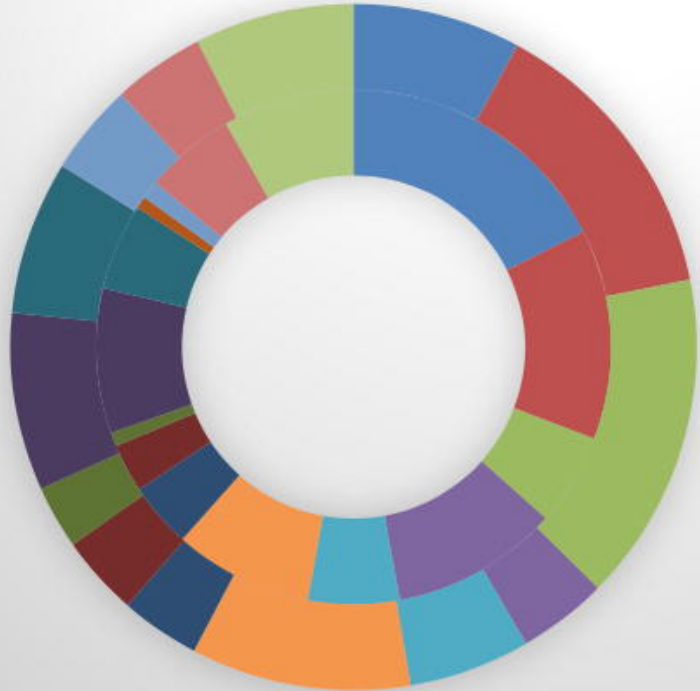

Pfbb

ㄷn b

$\mathrm{Cfbb}$

Ccts

affnb

affb

afts

- $1 / \alpha \mathrm{nb}$

$1 / \alpha b b$

घ $1 / \phi b b$

짐 $\beta \mathrm{fm}$

- $\beta \mathrm{mf}$

aㅔ $\mathrm{ksi}$ 


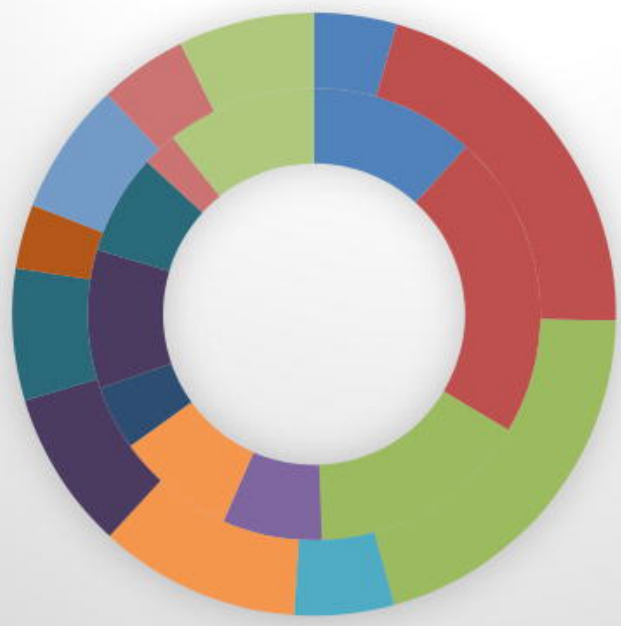

- Pfnb

afbb

cfnb

afbb

Ccts

affnb

affb

afts

-1/anb

-1/ $\alpha b b$

- $1 / \phi b b$

a $\beta \mathrm{fm}$

- $\beta m f$

asi 
(d) $3-4 \%$ HIV prevalence in males and 3-6\% HIV prevalence in females

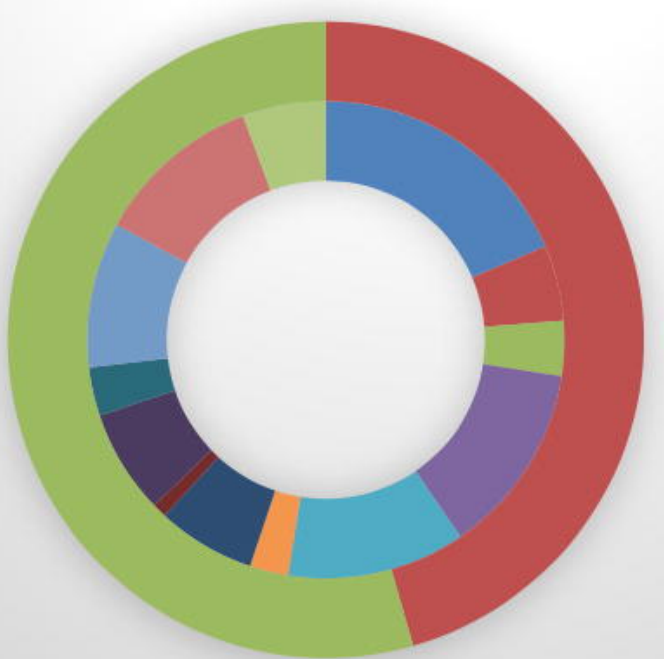


Female subgroup size (relative to total size of female population)

Brothel-based

FSWs
Non-brothel-

based FSWs
Adolescent female

$2+$ partners

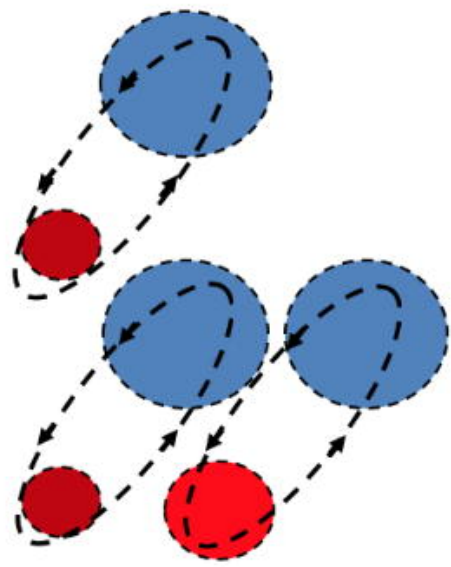

HIV Prevalence

$0-2 \%$ females

$3-4 \%$ males

HIV Prevalence

$2-3 \%$ females

$2-3 \%$ males

HIV Prevalence

3-6\% females

$0-2 \%$ males

\section{Sexual risk}

Description of population groups

Brothel-based FSW

Non-brothel based FSW

Female 2+ adolescent group

Clients of brothel-based and Non-brothel based FSWs

Male (2+) low-risk partners of female 2+ 
Description

Probability of HIV transmission

Relative size of Brothel-based FSWs group

Relative size of Non-brothel based FSWs group

Relative size of Females with 2+ partners group

Number of client partners of brothel-based female sex worker.

Number of client partners of non-brothel based FSWs

Number of partners of Females 2+ partners (these include client partners of both brothel-based and non-brothel based FSWs as well as males $2+$ partners)

Number of brothel based FSWs, clients of brothelbased FSW form partnerships with.

Number of non-brothel based FSWs, clients of nonbrothel based FSWs form partnerships with.

Consistency of condom use among Brothel-based

female sex workers

Consistency of condom use among Non-brothel based female sex workers

Consistency of condom use of females with $2+$ partners

Duration of brothel based female sex workers

Duration of non-brothel based female sex workers

Duration of Females 2+

Duration of brothel based clients

Duration of non-brothel based clients

Duration of Males $2+$

Percentage of sex acts of females $2+$ with client partners of brothel-based and non-brothel based FSWs

(Percentage of sex acts of females $\mathbf{2 +}$ with non-client male partners)
0.006-0.06

$0-1.1 \%$

$0.15-3 \%$

$0.1-20 \%$

$P_{F T S}$

$C_{F B B}^{C}$

$252-1092 / \mathrm{yr}$

$C_{F N R}^{C}$

$C_{C T S}^{T S}$

42-336/yr

$3-24 / \mathrm{yr}^{1}$

$C_{C B B}^{C}$

$12-48 / \mathrm{yr}$

$C_{C N B}^{C}$

$12-48 / \mathrm{yr}$

$f_{F B B}$

41-83\% (adjusted for efficacy)

$f_{F N B}$

$41-68 \%$

$f_{F T S}$

$10-39 \%$

$1 / \alpha_{B B}$

0.5-6 yrs

$1 / \alpha_{N B}$

0.5-6 yrs

$1 / \alpha_{T S}$

$1-15$ yrs

$1 / \varphi_{B B}$

5-10yrs

$1 / \varphi_{N B}$

5-10yrs

$1 / \varphi_{T S}$

5-20yrs

$\xi$

$0-100 \%$

$1-\xi$

$0-100 \%$ 


\begin{tabular}{|c|c|c|c|c|c|c|}
\hline $\begin{array}{l}\text { HIV prevalence } \\
\text { range }\end{array}$ & $\begin{array}{l}\text { West African } \\
\text { countries with HIV } \\
\text { prevalence in the } \\
\text { range }\end{array}$ & $\begin{array}{l}\text { Number } \\
\text { of } \\
\text { model } \\
\text { fits in } \\
\text { range }\end{array}$ & $\begin{array}{l}\text { Model } \\
\text { parameter }\end{array}$ & $\begin{array}{l}\text { Partial rank } \\
\text { correlation } \\
\text { coefficient } \\
\text { (PRCC) }\end{array}$ & p-value & $\begin{array}{l}\text { Key determinants of HIV prevalence (in order of } \\
\text { relevance) }\end{array}$ \\
\hline $0-6 \%$ & $\begin{array}{l}\text { All } 14 \text { countries in } \\
\text { Figure } 1\end{array}$ & 11162 & $\begin{array}{c}P_{F T S} \\
P_{F N B} \\
C_{F N B}^{C_{N B}} \\
1 / \alpha_{N B} \\
C_{C I S}^{T S} \\
\xi \\
P_{F B B} \\
C_{F B B}^{C} \\
\beta_{m f} \\
1 / \alpha_{B B} \\
f_{F N B} \\
f_{F B B} \\
\beta_{f m} \\
f_{F T S} \\
1 / \varphi_{B B}\end{array}$ & $\begin{array}{l}0.479 \\
0.359 \\
-0.2861 \\
-0.2477 \\
0.2377 \\
0.2248 \\
0.1909 \\
-0.1579 \\
0.1561 \\
-0.155 \\
0.1482 \\
0.111 \\
-0.0833 \\
-0.0315 \\
-0.0233 \\
0.0207\end{array}$ & $\begin{array}{l}<0.0001 \\
<0.0001 \\
<0.0001 \\
<0.0001 \\
<0.0001 \\
<0.0001 \\
<0.0001 \\
<0.0001 \\
<0.0001 \\
<0.0001 \\
<0.0001 \\
<0.0001 \\
<0.0001 \\
0.0009 \\
0.0138 \\
0.0288\end{array}$ & $\begin{array}{l}\text { 1.Population size of female } 2+\left(P_{F T S}\right) \\
\text { 2.Population size of Non-brothel based FSW } \\
\left(P_{F N B}\right) \\
\text { 3. Number of partners of Females } 2+ \\
\text { partners }\left(C_{r T s}^{T S}\right) \\
\text { 4. Proportion of female } 2+\text { sexual } \\
\text { partnerships formed with clients FSWs }(\xi) \\
\text { 5. Population size of Brothel based FSW } \\
\left(P_{F B B}\right)\end{array}$ \\
\hline $0-2 \%$ & $\begin{array}{l}9 \text { countries: } \\
\text { Niger } \\
\text { Senegal } \\
\text { Liberia } \\
\text { Birkina Faso } \\
\text { Sierra Leone } \\
\text { Benin } \\
\text { Mali } \\
\text { Gambia } \\
\text { Guinea }\end{array}$ & 2297 & $\begin{array}{c}P_{F N B} \\
P_{F B B} \\
P_{F T S} \\
\xi \\
1 / \alpha_{N B} \\
C_{C T S}^{T S} \\
1 / \alpha_{B B} \\
C_{F N B}^{C} \\
f_{F N B} \\
\beta_{m f}\end{array}$ & $\begin{array}{l}0.3359 \\
0.2449 \\
0.181 \\
0.1652 \\
-0.1527 \\
0.1313 \\
-0.1105 \\
-0.1094 \\
0.0709 \\
0.0385\end{array}$ & $\begin{array}{l}<0.0001 \\
<0.0001 \\
<0.0001 \\
<0.0001 \\
<0.0001 \\
<0.0001 \\
<0.0001 \\
<0.0001 \\
0.0007 \\
0.0661\end{array}$ & $\begin{array}{l}\text { 1.Population size of Non-brothel based } \\
\text { FSW }\left(P_{F N B}\right) \\
\text { 2 Population size of Brothel based FSW }\left(P_{F B B}\right) \\
\text { 3. Population size of female } 2+\left(P_{F T S}\right) \\
\text { 4. Proportion of female } 2+\text { sexual partnerships } \\
\text { formed with clients FSWs }(\xi) \\
\text { 5. Number of partners of Females } 2+ \\
\text { partners }\left(C_{C T S}^{T S}\right)\end{array}$ \\
\hline $2-3 \%$ & $\begin{array}{l}2 \text { countries: } \\
\text { Togo } \\
\text { Ghana }\end{array}$ & 1772 & $\begin{array}{l}P_{F N B} \\
P_{F B B} \\
P_{F T S} \\
\xi \\
C_{C T S}^{T S} \\
C_{F B B}^{C} \\
1 / \alpha_{N B} \\
1 / \alpha_{B B}\end{array}$ & $\begin{array}{l}0.0973 \\
0.097 \\
0.0966 \\
0.0723 \\
0.0692 \\
-0.0626 \\
-0.0577 \\
-0.0557\end{array}$ & $\begin{array}{l}<0.0001 \\
<0.0001 \\
0.0001 \\
0.0024 \\
0.0037 \\
0.0087 \\
0.0156 \\
0.0196\end{array}$ & $\begin{array}{l}\text { 1. Population size of Non-brothel based } \\
\text { FSW }\left(P_{F N B}\right) \\
\text { 2. Population size of Brothel based FSW }\left(P_{F B B}\right) \\
\text { 3. Population size of female } 2+\left(P_{F T S}\right) \\
\text { 4. Proportion of female } 2+\text { sexual partnerships } \\
\text { formed with clients FSWs }(\xi) \\
\text { 5. Number of partners of Females } 2+\text { partners } \\
\left(C_{C T S}^{T S}\right)\end{array}$ \\
\hline $3=6 \%$ & $\begin{array}{l}3 \text { countries: } \\
\text { Cameroon } \\
\text { Nigeria } \\
\text { Core d'Ivore }\end{array}$ & 1894 & $\begin{array}{c}P_{F T S} \\
C_{F N B}^{C} \\
C_{F B B}^{C} \\
\beta_{m f} \\
\beta_{f m} \\
f_{F B B} \\
1 / \alpha_{N B} \\
f_{F N B} \\
\xi \\
P_{F N B} \\
P_{F B B} \\
1 / \alpha_{B B} \\
C_{C T S}^{T S}\end{array}$ & $\begin{array}{l}0.3317 \\
-0.232 \\
-0.2155 \\
0.2023 \\
-0.176 \\
0.01721 \\
-0.1262 \\
0.1188 \\
0.1006 \\
0.0912 \\
-0.0665 \\
-0.0586 \\
0.0467\end{array}$ & $\begin{array}{l}<0.0001 \\
<0.0001 \\
<0.0001 \\
<0.0001 \\
<0.0001 \\
<0.0001 \\
<0.0001 \\
<0.0001 \\
<0.0001 \\
0.0001 \\
0.004 \\
0.0111 \\
0.0432\end{array}$ & $\begin{array}{l}\text { 1. Population size of female } 2+\left(P_{F T S}\right) \\
\text { 2. Transmission probability from male to } \\
\text { female }\left(\beta_{m f}\right) \\
\text { 3. Condom use among non-brothel-Based } \\
\text { FSWs }\left(f_{F N B}\right) \\
\text { 4. Proportion of female } 2+\text { sexual partnerships } \\
\text { formed with clients FSWs }(\xi) \\
\text { 5. Population size of Non-brothel based } \\
\text { FSW }\left(P_{F N B}\right)\end{array}$ \\
\hline
\end{tabular}




\begin{tabular}{|c|c|c|c|c|c|c|}
\hline $\begin{array}{l}\text { Prevalence } \\
\text { range }\end{array}$ & $\begin{array}{l}\text { West African } \\
\text { countries with HIV } \\
\text { prevalence in the } \\
\text { range }\end{array}$ & $\begin{array}{l}\text { Number } \\
\text { of } \\
\text { model } \\
\text { fits in } \\
\text { range }\end{array}$ & $\begin{array}{l}\text { Input } \\
\text { parameter }\end{array}$ & PRCC & p-value & $\begin{array}{l}\text { Key determinants of HIV prevalence (in order of } \\
\text { relevance) }\end{array}$ \\
\hline $0-4 \%$ & $\begin{array}{l}\text { All } 14 \text { countries in } \\
\text { Figure } 1\end{array}$ & 11162 & $\begin{array}{c}P_{F B B} \\
P_{F N B} \\
C_{C T S}^{T S} \\
1 / \alpha_{N B} \\
P_{F T S} \\
\xi \\
1 / \alpha_{B B} \\
C_{F B B}^{c} \\
\beta_{f m} \\
\beta_{m f} \\
C_{F N B}^{C} \\
f_{F B B} \\
f_{F N B} \\
f_{F T S}\end{array}$ & $\begin{array}{l}0.3646 \\
0.3265 \\
0.2431 \\
-0.1964 \\
0.1859 \\
0.1762 \\
-0.1701 \\
0.1342 \\
0.1015 \\
-0.1011 \\
-0.099 \\
-0.089 \\
0.0878 \\
-0.07\end{array}$ & $\begin{array}{l}<0.0001 \\
<0.0001 \\
<0.0001 \\
<0.0001 \\
<0.0001 \\
<0.0001 \\
<0.0001 \\
<0.0001 \\
<0.0001 \\
<0.0001 \\
<0.0001 \\
<0.0001 \\
<0.0001 \\
<0.0001\end{array}$ & $\begin{array}{l}\text { 1. Population size of Brothel-based FSWs }\left(P_{F B B}\right) \\
\text { 2. Population size of Non-brothel based FSW } \\
\left(P_{F N B}\right) \\
\text { 3. Number of partners of Females } 2+\text { partners } \\
\left(C_{C T S}^{T S}\right) \\
\text { 4. Population size of female } 2+\left(P_{F T S}\right) \\
\text { 5. Proportion of female } 2+\text { sexual partnerships } \\
\text { formed with clients FSWs }(\xi) \\
\text { 6. Size of the group of clients to brothel-based } \\
\text { FSWs }\left(C_{F B B}^{C}\right) \\
\text { 7.Transmission probability from male to female } \\
\left(\beta_{m f}\right)\end{array}$ \\
\hline $0-2 \%$ & $\begin{array}{l}12 \text { countries: } \\
\text { Niger } \\
\text { Senegal } \\
\text { Ghana } \\
\text { Liberia } \\
\text { Birkina Faso } \\
\text { Sierra Leone } \\
\text { Benin } \\
\text { Mali } \\
\text { Gambia } \\
\text { Guinea } \\
\text { Togo } \\
\text { Core d'Ivore }\end{array}$ & 2225 & $\begin{array}{c}P_{F N B} \\
P_{F B B} \\
C_{C T S}^{T S} \\
1 / \alpha_{N B} \\
\xi \\
\beta_{f m} \\
1 / \alpha_{B B} \\
C_{F B B}^{c} \\
\beta_{m f} \\
P_{F T S} \\
1 / \varphi_{B B}\end{array}$ & $\begin{array}{l}0.3063 \\
0.2981 \\
0.1578 \\
-0.1248 \\
0.1066 \\
0.1041 \\
-0.1036 \\
0.0783 \\
-0.0691 \\
0.0648 \\
-0.0503\end{array}$ & $\begin{array}{l}<0.0001 \\
<0.0001 \\
<0.0001 \\
<0.0001 \\
<0.0001 \\
<0.0001 \\
<0.0001 \\
0.0002 \\
0.0012 \\
0.0023 \\
0.0181\end{array}$ & $\begin{array}{l}\text { 1. Population size of non-brothel-based FSWs } \\
\left(P_{F N B}\right) \\
\text { 2. Population size of Brothel based FSW }\left(P_{F B B}\right) \\
\text { 3. Number of partners of Females } 2+\text { partners } \\
\left(C_{C T S}^{T S}\right) \\
\text { 4. Proportion of female } 2+\text { sexual partnerships } \\
\text { formed with clients FSWs }(\xi) \\
\text { 5.Transmission probability from male to female } \\
\left(\beta_{m f}\right)\end{array}$ \\
\hline $2-3 \%$ & $\begin{array}{l}1 \text { countries: } \\
\text { Cameroon }\end{array}$ & 2317 & $\begin{array}{c}1 / \alpha_{N B} \\
P_{F N B} \\
P_{F B B} \\
C_{C T S}^{T S} \\
f_{F N B}\end{array}$ & $\begin{array}{l}-0.0797 \\
0.062 \\
0.0588 \\
0.045 \\
0.0466\end{array}$ & $\begin{array}{l}0.0001 \\
0.003 \\
0.0048 \\
0.0308 \\
0.0323\end{array}$ & $\begin{array}{l}\text { 1. Population size of non-brothel-based FSWs } \\
\left(P_{F N B}\right) \\
\text { 2. Population size of Brothel based FSW }\left(P_{F B B}\right) \\
\text { 3. Number of partners of Females } 2+\text { partners } \\
\left(C_{C T S}^{T S}\right) \\
\text { 4. Condom use among non-brothel based FSWs } \\
\left(f_{F N B}\right)\end{array}$ \\
\hline $3-4 \%$ & $\begin{array}{l}1 \text { country: } \\
\text { Nigeria }\end{array}$ & 2402 & $\begin{array}{l}P_{F B B} \\
P_{F N B}\end{array}$ & $\begin{array}{l}0.0467 \\
0.0391\end{array}$ & $\begin{array}{l}0.0225 \\
0.0504\end{array}$ & $\begin{array}{l}\text { 1.Population size of Brothel-based FSWs }\left(P_{F B B}\right) \\
\text { 2.Population size of Non-brothel based FSW } \\
\left(P_{F N R}\right)\end{array}$ \\
\hline
\end{tabular}

